\title{
The solitary pulmonary nodule: not always bronchogenic carcinoma
}

\author{
Bobbak Vahid*, Frank T. Leone
}

Department of Pulmonary and Critical Care Medicine, Thomas Jefferson University, 1015 Chestnut Street, Suite M-100, Philadelphia, PA 19107, USA

Received 16 October 2005; accepted 15 May 2006

KEYWORDS

Lymphoma;

Pulmonary nodule

\section{Case report}

An 87 year-old woman was referred to the pulmonary clinic following the incidental finding of a right lung nodule. She had a smoking history of 50 pack years. Her past medical history was significant for coronary artery disease and chronic obstructive pulmonary disease (COPD). The patient had no cough, hemoptysis, fever, night sweats, or weight loss. Physical examination revealed a temperature of $37.5^{\circ} \mathrm{C}$, blood pressure of $128 / 60 \mathrm{~mm} \mathrm{Hg}$, heart rate of 88 beats/min, and oxygen saturation of $92 \%$ on room air.

\footnotetext{
* Corresponding author. Tel.: +1 215955 6591; fax: +1 2159550830 .

E-mail address: Bobbak.vahid@mail.tju.edu (B. Vahid).
}

There was no palpable lymphadenopathy in the cervical, supraclavicular, and axillary regions. Chest, cardiac, and abdominal examinations were unremarkable. Spirometry revealed a Forced Expiratory Volume in one second (FEV1) of $800 \mathrm{ml}$. A chest radiograph and a computed tomography (CT) scan of the chest showed a $2.3 \mathrm{~cm}$ spherical mass in the right lower lobe with no evidence of mediastinal lymphadenopathy (Figure 1). Bronchoscopy was performed since sputum cytology was non-diagnostic. Transthoracic CT-guided fine needle aspiration of the lesion was done. Cytology revealed low-grade B-cell lymphoma. Based on her co-morbidities and very low FEV1, she was a poor candidate for surgery, radiotherapy or chemotherapy. The decision was made to observe her without treatment. During 18 


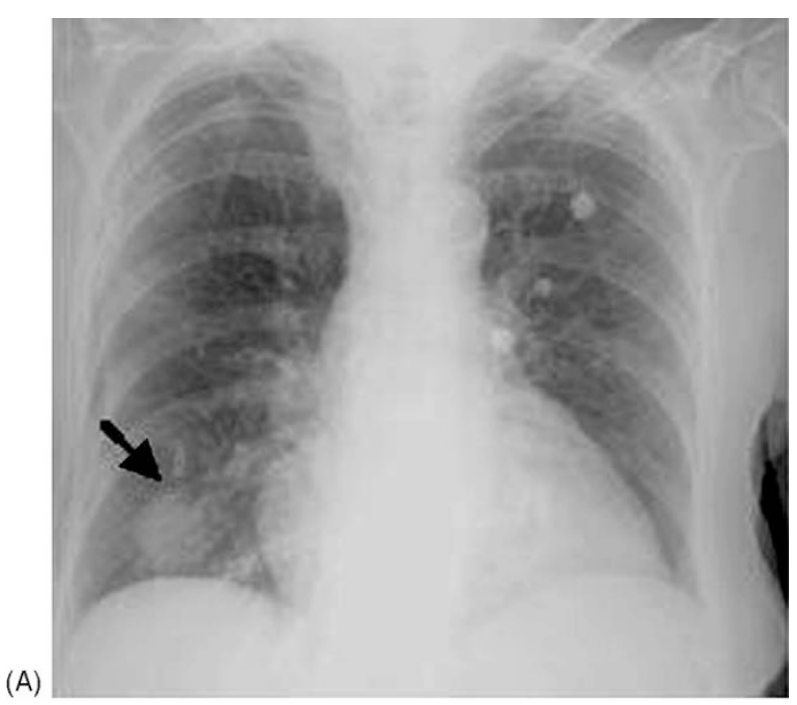

(B)

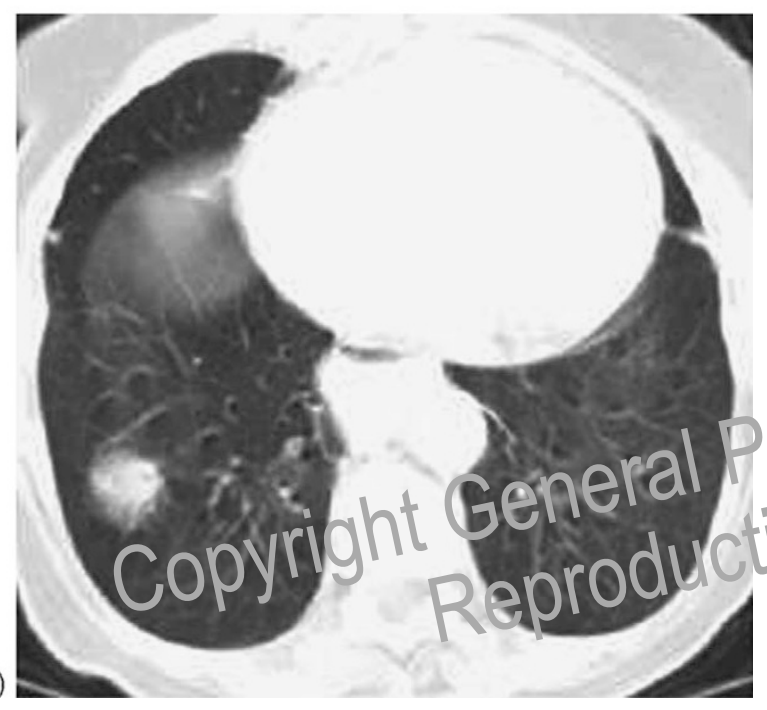

Figure 1 (A) Chest radiograph showing a right lower lobe mass (black arrow). (B) CT scan of the chest showing a $2.3 \mathrm{~cm}$ spherical mass in the right lower lobe with illdefined borders.

months of follow-up after presentation, the patient remained asymptomatic and repeat chest CT scan revealed no new lesions and only minimal growth of the mass.

\section{Discussion}

A solitary lung nodule (SLN) is an intraparenchymal round lesion that is less than $3 \mathrm{~cm}$ in diameter and is not associated with atelectasis and adenopathy. Lesions greater than $3 \mathrm{~cm}$ are defined as lung masses and are often malignant. A SLN is noted in 1 in 500 chest radiographs. Infectious granulomas (about $80 \%$ ) and hamartomas (about 10\%) are the most common benign causes of SLN. Other benign etiologies for SLN are rheumatoid nodules, intrapulmonary lymph nodes, and sarcoidosis. SLN may also be malignant. Bronchogenic carcinoma and solitary pulmonary metastases may be found in $35 \%$ and $23 \%$ of SLNs, respectively $[1,2]$.

Primary pulmonary non-Hodgkin's lymphoma is a rare disease and includes $0.4 \%$ of all lymphomas [3]. The definition of primary pulmonary lymphoma (PPL) includes involvement of lung parenchyma or bronchi with monoclonal lymphoid cells in the absence of extrapulmonary evidence of lymphoma at diagnosis and during the subsequent three months. There are three major forms of PPL that can present as a SLN (4):

1. Bronchial-associated lymphoid tissue (BALT) lymphoma

2. Low-grade B-cell PPL

3. High-grade B-cell PPL

BALT lymphoma is the most common form of PPL and accounts for about $80 \%$ of cases in pathological series'. BALT lymphoma is a lowgrade B-cell lymphoma [4]. Chronic scimulation of bronchial mucosa-related tynptid tissue as a result of infection. nioking, or autoimmune distase, Ians been related to the development of CALL' lymphoma. "MAit ymphoma has an indolent course and $r \in$ rndins limited to the lungs for long pieric as of time before becoming disseminated [5]. Fever, night sweats, cough and chest pain are uncommon. Anaemia and elevated levels of lactate dehydrogenase (LDH) are also uncommon. BALT lymphoma has a favorable prognosis. Treatment options are close observation, radiotherapy, surgery, and chemotherapy [4,5].

Low-grade B-cell lymphoma represents less than $10 \%$ of PPLs and is diagnosed when the lymphoma dose not meet the histological criteria of BALT lymphoma. High-grade B-cell PPL accounts for about $10 \%$ of cases. This form of lymphoma occurs in patients after heart or lung transplantation or in patients with human immunodeficiency infection [5].

Although rare, PPL should be considered in the differential diagnosis of a SLN. Low-grade B-cell PPL has a favorable prognosis and in patients who are poor candidates for treatment, a strategy of "wait and see" is reasonable.

\section{References}

[1] Ost D, Fein AM, Feinsilver SH. The Solitary Pulmonary Nodule. N Eng J Med 2003;348:2535-42. 
[2] Tan BB, Flaherty KR, Kazerooni EA, lannettoni MD. The Solitary Pulmonary Nodule. Chest 2003;123:89S-96S.

[3] Ferraro P, Trastek VF, Adlakha H, et al. Primary Non-Hodgkin's Lymphoma of the Lung. Ann Thorac Surg 2000;69:993-7.
[4] Cadranel J, Wislez M, Antoine M. Primary Pulmonary Lymphoma. Eur Resp J 2002;20:750-62.

[5] Kim JH, Lee S, Park J, et al. Primary Pulmonary NonHodgkin's Lymphoma. Jpn J Clin Oncol 2004;34:510-4.

Available online at www.sciencedirect.com Science 0 DiREct

\section{Available online at http://www.thepcrj.com}

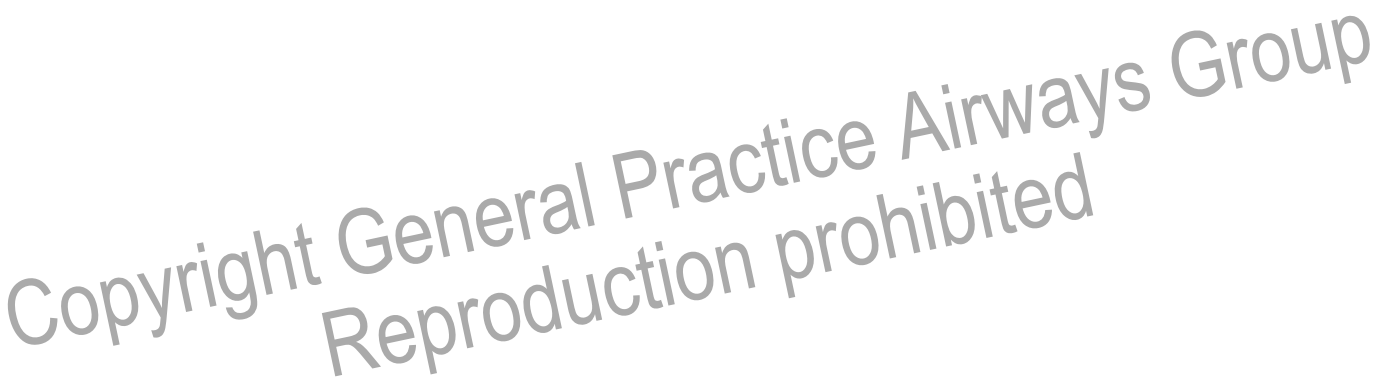

